\title{
Cuidado sistematizado em pré-operatório cardíaco: Teoria do Cuidado Transpessoal na perspectiva de enfermeiros e usuários
}

\author{
Systematized care in cardiac preoperative: Theory of Human Caring in the perspective of nurses and users \\ Cuidado sistematizado en preoperatorio cardiaco: Teoría del Cuidado Humano \\ en la perspectiva de las enfermeras y usuarios
}

\section{Thais Vasconselos Amorim', Cristina Arreguy-Sena', Marcelo da Silva Alves', Anna Maria de Oliveira Salimena'}

\author{
' Universidade Federal de Juiz de Fora, Faculdade de Enfermagem, \\ Programa de Pós-Graduação em Enfermagem. Juiz de Fora-MG, Brasil.
}

Submissão: 19-12-2012 Aprovação: 25-06-2014

\section{RESUMO}

Estudo de caso que objetivou desvelar, a partir da adoção da Teoria do Cuidado Transpessoal, os significados do relacionamento interpessoal terapêutico entre enfermeiro e usuário, sobre a visita pré-operatória de enfermagem após a vivência do processo cirúrgico. A amostra, de conveniência, foi constituída por três enfermeiros e três usuários de uma instituição que possui cadastro atualizado para realizar cirurgia de alta complexidade cardiovascular, perfazendo nove combinações de interações terapêuticas. Foram utilizados impressos estruturados segundo a teoria de Jean Watson e as taxonomias North American Nursing Diagnosis Association, Nursing Intervention Classification e Nursing Outcome Classification. Os aspectos éticos e legais de pesquisa envolvendo seres humanos foram assegurados. Nos resultados, identificaram-se três clusters para apreender a significação da visita pré-operatória pelos usuários e cinco clusters para apreender a percepção dos enfermeiros ao vivenciarem esta experiência clínica. Descritores: Cuidados de Enfermagem; Assistência Centrada no Paciente; Enfermagem Perioperatória; Planejamento de Assistência ao Paciente.

\section{ABSTRACT}

This is a case study research that aimed to know, with the adoption of the Theory of Human Caring, the meanings of therapeutic interpersonal relationship between nurse and user on the preoperative nursing visit after the experience of the surgical process. The convenience sample was composed of three nurses and three users of an institution that has updated records to perform highly complex cardiovascular surgery, comprising nine combinations of therapeutic interactions. It was used instruments, structured according to the theory of Jean Watson and North American Nursing Diagnosis Association, Nursing Intervention Classification and Nursing Outcomes Classification taxonomies. The legal and ethical aspects of research involving human subjects were assured. The results revealed three clusters to grasp the significance of preoperative visits by users and five clusters to capture the perception of nurses when they experience this clinical experience.

Key words: Nursing Care; Patient-Centered Care; Perioperative Nursing; Patient Care Planning.

\section{RESUMEN}

Estudio de caso que objetivó conocer, mediante la Teoría del Cuidado Transpersonal, los significados de la relación terapéutica interpersonal entre enfermera y usuario con respecto a la visita preoperatoria de enfermería después de la experiencia del procedimiento quirúrgico. La muestra, de conveniencia, fue composta por tres enfermeras y tres usuarios de una institución que realiza cirugías cardiovasculares de alta complejidad, comprendiendo nueve combinaciones de interacciones terapéuticas. Utilizóse un impreso, estructurado de acuerdo a la teoría de Jean Watson y las taxonomías North American Nursing Diagnosis Association, Nursing Intervention Classification e Nursing Outcome Classification. Los aspectos éticos y legales de la investigación con seres humanos fueran asegurados. Los resultados revelaron tres agrupamientos para captar el significado de la visita preoperatoria por los usuarios; y cinco agrupamientos para captar la percepción de las enfermeras cuando experimentan esta experiencia clínica. Palabras clave: Atención de Enfermería; Atención Dirigida al Paciente; Enfermería Perioperatoria; Planificación de Atención al Paciente. 


\section{INTRODUÇÃO}

Estatísticas ministeriais destacam as Doenças Isquêmicas Cardíacas como causa de morte importante no Brasil ${ }^{(1)}$. Para dar resolutividade ao processo obstrutivo, a cirurgia cardíaca surge como alternativa diante da impossibilidade de recuperação da perfusão tissular miocárdica, quer por intervenções terapêuticas farmacológicas, ou por procedimentos que aumentem a permeabilidade coronariana, a exemplo do uso de balões e stents. Na literatura, é conferido destaque a três tipos de cirurgia, sendo o tipo mais comum de cirurgia reconstrutora a Revascularização do Miocárdio ${ }^{(2)}$.

Independente do tipo de procedimento cirúrgico recomendado, a proximidade de um ato operatório remete o ser humano ao temor pela própria existência e à incerteza quanto aos resultados da intervenção. No caso de uma cirurgia cardíaca, o fato de o coração simbolizar o sentimento e representar a fonte da vida, pode favorecer o surgimento de ansiedade, temor, medo e incertezas. Tais sentimentos, na medida em que retratam respostas do indivíduo ou da família diante de uma situação contextualizada no processo saúde/doença e num determinado momento da vida, configuram-se como diagnósticos de enfermagem emergentes no período pré-operatório ${ }^{(3-5)}$.

Outra resposta humana emergente nas situações em que há recomendação para a realização de uma cirurgia cardíaca é a dúvida ${ }^{(3)}$. Ela pode ocorrer tanto entre os usuários como entre familiares ou acompanhantes, e se configura como evidência clínica compatível com a atuação de enfermeiros na perspectiva de redução do desconhecimento e da promoção de ações integrativas no tocante à orientação/educação.

Neste contexto, a visita pré-operatória (VPO), primeira etapa da Sistematização da Assistência de Enfermagem Perioperatória (SAEP), constitui uma estratégia capaz de favorecer o levantamento individual das necessidades humanas. Representa um dos momentos autênticos de interação entre o profissional e o usuário, sendo instrumento que otimiza o cuidado perioperatório, no qual o enfermeiro atua de maneira expressiva, proporcionando apoio emocional, atenção e orientações nestes instantes em que o usuário experimentará diversos sentimentos ${ }^{(6)}$.

Ao realizar a VPO, o enfermeiro deve aplicar o Processo de Enfermagem, considerando que este deve "estar baseado num suporte teórico que oriente a coleta de dados, o estabelecimento de diagnósticos de enfermagem e o planejamento das ações ou intervenções de enfermagem; e que forneça a base para a avaliação dos resultados alcançados ${ }^{\prime \prime(7)}$.

Diante do exposto, a presente investigação adotou o significado do relacionamento interpessoal terapêutico entre enfermeiro/usuário baseado na Teoria do Cuidado Transpessoal de Jean Watson, considerando a representação da visita pré-operatória como ferramenta do cuidado de enfermagem capaz de contemplar as vivências e as formas de enfrentamento do processo cirúrgico cardíaco, a partir de uma avaliação retrospectiva realizada pelos sujeitos no período de pós-operatório tardio.

A presente investigação tem alicerce nas seguintes argumentações: 1) atendimento da recomendação para que o cuidado profissional seja sistematizado e estruturado em bases teóricas e filosóficas da própria categoria (Teoria do Cuidado Transpessoal de Jean Watson); 2) o enfermeiro utilizar as impressões dos usuários como critérios mensurativos para a avaliação dos resultados de enfermagem e 3) a cirurgia cardíaca envolver a dimensão cultural e emocional como componentes intervenientes sobre o processo de recuperação do usuário em uma perspectiva de cuidado de enfermagem.

Objetivou-se compreender os significados do relacionamento interpessoal terapêutico entre enfermeiro e usuário, a partir da adoção da Teoria do Cuidado Transpessoal, sobre a visita pré-operatória de enfermagem após a vivência do processo cirúrgico.

\section{A TEORIA DO CUIDADO TRANSPESSOAL}

A Teoria do Cuidado Transpessoal emergiu no final da década de 70 a partir dos resultados de estudos realizados pela autora durante seu doutorado, culminando com a publicação de seu primeiro livro, intitulado "A Filosofia e a Ciência do Cuidado", em que refletiu acerca de novos conceitos de cuidado, ressignificando a Enfermagem e sua (inter)relação com o usuário ${ }^{(8)}$.

Nas últimas três décadas, houve uma percepção crescente da dimensão ética e humana do cuidado em enfermagem, cujo ponto de partida alicerçou-se no aprofundamento das relações humanas entre aqueles que cuidam e os que são cuidados. Por isso, revisaram-se em 2008, os dez fatores de cuidados (Carative Factors/Caritas Processes) explicados a seguir: 1- Adotar valores altruístas e a pratica da bondade consigo e com os outros; 2- estimular a fé e a esperança; 3- ser sensível consigo mesmo e com o próximo, alimentando crenças e práticas individuais; 4- desenvolver a ajuda com relações de confiança e carinho; 5- promover e aceitar a expressão de sentimentos positivos e negativos; 6- utilizar com criatividade métodos científicos para resolver problemas de tomada de decisão; 7- compartilhar o ensino e a aprendizagem que atenda as necessidades e estilos individuais de compreensão; 8- criar um ambiente de cura física e espiritual que respeite a dignidade humana; 9- assistir necessidades humanas básicas: físicas, emocionais e espirituais; 10- ser aberto a mistérios e permitir a entrada de milagres). Tal concepção possibilitou perceber o ser humano em sua dimensão metafísica e direcionar o conceito de healing (cura) como recomposição daqueles que experimentam um processo desarmônico de saúde-doença ${ }^{(8)}$.

Os pressupostos teóricos e os fatores de cuidado ampliaram a visão do enfermeiro em direção à integralidade do cuidar, somando as experiências dos indivíduos envolvidos no tocante ao autoconhecimento, promoção de ensino-aprendizagem mútua, expressão de sentimentos, manutenção de um ambiente de cuidado terapêutico dos pontos de vista físico, espiritual, emocional e sociocultural, alicerçados pelos conhecimentos técnico-científicos ${ }^{(9)}$.

A Enfermagem brasileira agregou a teoria a partir de pesquisas realizadas nos Programas de Pós-Graduação Stricto sensu, sendo os estudos qualitativos os predominantes. Eles direcionam-se aos usuários e familiares, quer internados em setores de terapia intensiva, em acompanhamento por 
tratamento hemodialítico, oncológico ou em ambiente domiciliar, vinculado à saúde da mulher, de adultos ou idosos ${ }^{(10-11)}$.

Cabe acrescentar que, além dos enfoques destacados, a concepção do Cuidado Transpessoal destacou a permuta de impressões conscienciais ${ }^{(8)}$, e portanto, fenomenológicas. Isto equivale a dizer que o enfermeiro que pretende embasar o processo de cuidado nesta teoria deve compartilhar da concepção de que as transformações no cenário da saúde dar-se-ão a partir de suas próprias transformações como indivíduo e da maneira como vivencia o ato de cuidar, traduzindo-o como uma experiência única e ontológica de si e do outro.

\section{MÉTODO E TÉCNICAS}

Delineamento: Pesquisa qualitativa delineada em um estudo de caso, método pelo qual pode-se compreender de modo aprofundado uma situação em particular visando mostrá-la por completo em sua realidade ${ }^{(12)}$. Neste estudo, a ênfase está alicerçada na capacidade da Teoria do Cuidado Transpessoal subsidiar o estabelecimento de um relacionamento interpessoal terapêutico entre o enfermeiro/usuário submetido à cirurgia cardíaca, a ponto de captar as impressões dos usuários como critérios mensurativos para a avaliação dos resultados de enfermagem.

Cenário do Estudo: Instituição de Saúde de médio porte da Zona da Mata Mineira que possui cadastro atualizado para realização de cirurgia de alta complexidade cardiovascular.

Participantes: Amostra de conveniência composta por enfermeiros e usuários. Foram elegíveis: 1) enfermeiros que atuam em setor cirúrgico, bloco cirúrgico e unidade de terapia intensiva, ou seja, atendem a clientela de usuários de cirurgia cardíaca e que possuem vínculo empregatício com a instituição onde os dados foram coletados e 2) usuários que estavam em período de pré-operatório de cirurgia cardíaca, de ambos os gêneros, com idade superior a 21 anos de idade e que expressavam verbalmente com coerência. Em ambos os casos foram considerados participantes voluntários não remunerados. Participaram três enfermeiros, sendo um de cada setor e três usuários, perfazendo nove possibilidades de binômios enfermeiro/usuário com suas respectivas combinações de interações, percepções e avaliações. O convite individual foi o processo de recrutamento dos participantes.

Instrumento e processo de coleta de dados: Foram elaborados impressos para nortear o planejamento da assistência de enfermagem aos indivíduos no período de pré-operatório de cirurgia cardíaca. Impressos estruturados a partir da Teoria do Cuidado Transpessoal de Jean Watson e das taxonomias: NANDA International (que aborda os diagnósticos de enfermagem), NIC (aborda as intervenções de enfermagem) e NOC (aborda os resultados de enfermagem) - taxonomias NNN. Para familiarização dos enfermeiros com os mesmos, foram realizados grupos de estudos até que eles tivessem conhecimento da teoria e se considerassem esclarecidos a respeito de suas dúvidas.

Posteriormente, os enfermeiros aplicaram estes impressos na sua prática clínica com os usuários em fase de pré-operatório de cirurgia cardíaca. Os enfermeiros e usuários participantes da investigação foram entrevistados individualmente e tiveram suas falas gravadas a partir das seguintes questões norteadoras: 1) Usuários: Como o(a) senhor(a) percebeu a visita pré-operatória de enfermagem e as ações de enfermagem recebidas? 2) Enfermeiros: Para você, o quanto o referencial teórico do cuidado transpessoal e as taxonomias North American Nursing Diagnosis Association (NANDA), Nursing Intervention Classification (NIC) e Nursing Outcome Classification (NOC) foram capazes de captar as respostas dos usuários diante do processo cirúrgico cardíaco e respaldar sua atuação profissional? Estas questões permitiram captar os discursos dos sujeitos participantes. Dados coletados no período de janeiro a março de $2012 \mathrm{com}$ tempo médio de quinze minutos e variabilidade de dez a vinte minutos de duração.

Consolidação e Análise dos dados: O discurso obtido com os participantes foi transcrito para os programas Word for Windows e NVivo versão 9,0. A escolha pelo NVivo deveu-se ao fato de: ser ferramenta capaz de focar a análise qualitativa na perspectiva da relação dialógica que se estabeleceu entre o enfermeiro/ usuários que realizaram cirurgia cardíaca; possibilitar exploração estruturada, sistemática e aprofundada dos discursos; dispor de técnicas de codificação (exploração e extração) de informações em diferentes tipos de buscas de texto e de codificação, que precedem e favorecem a análise e a interpretação dos dados a partir da construção das similaridades, divergências e aproximações entre os conteúdos emergentes e minimizar o tempo e o esforço na etapa de categorização dos dados.

Foram utilizadas quatro etapas na análise dos dados: 1) pré-análise, desencadeada pela leitura flutuante para conhecimento e criação de impressões iniciais, seguida de leitura aprofundada para estabelecimento das hipóteses sobre as ligações entre os conteúdos e impressões do binômio enfermeiro/ usuário com articulação dos mesmos; 2) escolha de estratégia de análise baseada na percepção dos sujeitos sobre a temática objetivada, o que envolveu a reunião das informações em unidades de codificação que, após agregadas, permitiram inferências e interpretações iniciais; 3 ) aproximação entre unidades de registro e de significado com o retorno dos fragmentos do texto para o contexto onde foram gerados, utilizando as regras de enumeração, intensidade, direção e estética dos conteúdos; 4) seleção de ferramentas compatíveis para apreensão da operacionalização da classificação dos elementos que compõe o conjunto do discurso e reunião em grupos de unidades de registros em situações mutuamente exclusivas ou complementares, com agrupamento em clusters por similaridade de palavras e utilização do coeficiente de Pearson para descrever o grau de correlação entre os clusters emergentes.

Aspectos éticos: Foram assegurados os aspectos éticos e legais de pesquisa envolvendo seres humanos, conforme Resolução 196/96 e suas complementares, sendo o projeto submetido a Comitê de ética com parecer número 305/2011.

\section{RESULTADOS}

Em relação ao gênero dos usuários, duas eram mulheres e um homem. A média de idade foi de 53 anos. As mulheres possuíam o ensino fundamental incompleto e o entrevistado masculino, o ensino médio completo. Todos declararam não 
terem recebido visita pré-operatória em cirurgias anteriores. A prevalência de cirurgia cardíaca foi do tipo reconstrutora (Revascularização do Miocárdio), seguida da modalidade reparadora (Correção de Comunicação Interatrial).

Quanto aos profissionais enfermeiros, os entrevistados foram do gênero feminino, atuavam em setores de clínica médico-cirúrgica, centro cirúrgico e Unidade de Terapia Intensiva (UTI). Duas enfermeiras possuíam especialização lato sensu em UTI neonatal e Urgência e Emergência; uma estava em fase de conclusão da Pós Graduação em Cardiologia. A média de idade das participantes foi de 29 anos e o tempo médio de formação quatro anos. Apenas uma enfermeira realizava a visita pré-operatória de enfermagem, sendo o procedimento desconhecido para as outras entrevistadas. Todas declararam que pela primeira vez teriam a experiência de utilizar um instrumento baseado em um referencial teórico e aplicar as taxonomias NNN.

Foram identificados três grupos de significados, também denominados clusters, para apreender a significação da VPO pelos usuários e cinco clusters para apreender a percepção dos enfermeiros ao vivenciarem esta experiência clínica propiciada a partir da presente investigação. O relato de experiência, a reação ao cuidado e o enfrentamento do processo cirúrgico foram os clusters identificados entre os usuários.

O relato de experiência abrangeu a deficiência do conhecimento em relação ao procedimento cirúrgico e à lembrança no pós-operatório das orientações recebidas na VPO.

Eu não sabia que ia fazer cirurgia. Na verdade eles falaram que era coisinha simples que ia resolver com o cateterismo, que não precisava de cirurgia nem nada. (Usuário 2)

Aconteceu tudo que vocês falaram. Doeu o tubo e o dreno na hora de tirar, dói muito, né filha! (Usuário 4)

A reação ao cuidado na primeira fase da SAEP emerge nos discursos como algo, a princípio, assustador por conta do detalhamento dos procedimentos no trans e pós-operatórios, visualização das fotos da Unidade de Terapia Intensiva e manipulação dos insumos (tubos, drenos, cateteres).

Que ela (enfermeira) me explicou; aí me assustei, por que vi que era uma cirurgia bem séria. Por que ela (enfermeira) veio e explicou tudo, aí eu fiquei meio assustada. Andei chorando, por que eu sou muito chorosa! Depois acalmei! (risos) (Usuário 2)

Porém, a avaliação da assistência prestada pelo enfermeiro e equipe de enfermagem denotou melhor enfrentamento e percepção positiva do cuidado.

Se eu fizesse essa cardíaca sem saber antes, eu ia ficar descontrolada! Quando eu acordasse na UTI, eu ia pensar que eu estava muito ruim [...] Eu ia pensar que não era normal o tubo, o dreno e que eu devia estar muito ruim. (Usuário 2)

Ah! Se eu não tivesse a visita pré-operatória eu não ia não. Não ia fazer (a cirurgia) não. Só delas (as enfermeiras) me explicaram tudo direitinho, o que ia acontecer. Se não fosse elas, eu não ia fazer a cirurgia não. Eu me lembro de cuidados de enfermagem antes da cirurgia. Foram muitos (cita alguns nomes de profissionais). Meu medo diminuiu e a ansiedade também. (Usuário 3)

Antes eu não sabia de nada; tinha dúvidas. Sabia que ia fazer uma cirurgia, mas não sabia como era, não sabia de nada. E vocês passaram a orientação e eu fiquei tranquilo! Engraçado que eu fui lembrar das orientações lá na UTI! Eu sabia de tudo que estava em mim, por que vocês me falaram graças a Deus! Antes e após eu percebi os cuidados. Foi muito bom! Eu agradeço muito! Eu perguntei mais algumas dúvidas e fui esclarecido. Me senti apoiado. (Usuário 4)

Utilizou-se o coeficiente de Pearson a fim de descrever o grau de correlação entre os clusters do usuário, sendo encontrados para o nó da Avaliação da Assistência a partir do Enfrentamento e Percepção do Cuidado os valores representados respectivamente por $=0,889792 \mathrm{e}=0,896525$, indicando forte correlação entre as categorias.

Para os enfermeiros, os clusters agruparam-se em cinco: Facilidades e benefícios do referencial teórico adotado nos impressos, Resultados obtidos a partir desta experiência, Avaliação dos impressos quanto à utilidade, O quanto a SAE pode ser traduzida a partir do impresso utilizado, habilidade com os impressos e com a teoria de enfermagem adotada.

A instrumentalização do cuidado de enfermagem a partir de impressos baseados em teoria e em taxonomias como NANDA, NIC e NOC não fazia parte da rotina do enfermeiro na instituição, limitando-o a princípio.

Nós não temos uma teoria que embase o cuidado. (Enfermeiro 1)

Antes (da presente experiência com a SAE com teoria) a gente só abordava, mas não havia intervenções. A gente só explicava o procedimento. Já os diagnósticos e intervenções, igual eu falei [...]. Eu senti dificuldade pela falta de prática, mas com o estudo e a prática, não tomaria tanto tempo, faria com mais facilidade. (Enfermeiro 3)

Porém, ao avaliar os resultados obtidos diante da Sistematização da Assistência de Enfermagem fundamentada cientificamente, o profissional percebeu a satisfação do usuário com o cuidado prestado, mensurando com maior propriedade a efetividade das intervenções implementadas.

Eu vi de maneira positiva essa resposta quando ele chegava no bloco. O paciente chegava no bloco e eu percebia que os pontos que a gente levantou estavam mais seguros, mais embasados. Eu senti o paciente mais seguro, eu senti que ele tinha um ponto de referência, enfermeiro/técnico de enfermagem. Ele conhecia melhor o ambiente, a estrutura, parecia mais seguro do que 24 horas anteriores. Então, o fator segurança foi muito visível para mim, maior segurança por parte dele. (Enfermeiro 3) 
Outra fala remontou aos fatores de cuidado propostos pela teoria adotada, entendidos pelo enfermeiro como os resultados a serem alcançados e permitindo conectividade ao diagnóstico de enfermagem levantado a partir da coleta de dados.

(A Teoria do Cuidado Transpessoal subsidiou) na verdade, na hora de fazer o diagnóstico relacionando os fatores (fatores de cuidado - Clinical Caritas), a gente liga uma coisa a outra. (Enfermeiro 2)

Outro resultado obtido a partir desta experiência foi mencionado pelo profissional através da perspectiva que os impressos possibilitam de direcionamento do autoconhecimento e da intencionalidade de entrada no universo do outro de maneira integral, buscando compreendê-lo em seus limites e dificuldades.

O cuidado de nós mesmos para saber cuidar do outro, então o autoconhecimento, filtrando essas impressões para saber a necessidade do outro. Essa abordagem ajuda também ao paciente, para ele se abrir, dá abertura para ele falar, por exemplo: Eu não vou conseguir largar o cigarro, até ontem eu fumava dois maços, agora estou internado aqui e não posso fumar mais nada, eu vou operar do coração, mas não vou conseguir largar o cigarro. Como que vai ser? Se a abordagem for humana, ele tem maior abertura para a mudança do que simplesmente falar: Você não vai mais fumar por que você é cardiopata. (Enfermeiro 3)

Na avaliação da utilidade dos impressos à luz de uma teoria de enfermagem, evidenciou-se nas falas a oportunidade que este confere, de agregar valor científico a um momento peculiar como o pré-operatório de cirurgia cardíaca.

Justamente essa teoria em uma fase que é assim difícil. Muitas vezes a gente chega lá (junto ao usuário) e o paciente não sabe nada e ela (teoria) esclarece. Então a gente vê $o$ quanto que a gente precisa de frisar mais. (Enfermeiro 1)

Quando a gente vai fazer um exame físico, entrar num primeiro contato com o paciente, conversar com ele para a admissão, é bem menos aprofundado. Com os instrumentos, a gente acaba entrando em mais detalhes. Por que com os impressos você busca tudo. A Coleta de dados do impresso, se você seguir, você coleta tudo da vida do paciente de forma aprofundada, desde a parte clínica até a parte sentimental, a vida, o social. (Enfermeiro 2)

Principalmente nesse campo de atuação, no pré-cirúrgico de uma cirurgia cardíaca que envolve muitos fatores religiosos, emocionais, de família, esse cuidado transpessoal é o principal. Então, a teoria encaixa muito bem com esse fator (múltiplas dimensões do paciente), apesar de ser também muito abrangente. Ela atende muito bem, por que os fatores físicos neste momento são muito pequenos perto dos emocionais para o paciente. Essa atenção, esse cuidado que a gente volta, "como você sente, como você está", ele sente a diferença, por que quebra esse parâmetro da enfermagem só aferir sinais vitais e está tudo bem. (Enfermeiro 3)

A Sistematização da Assistência de Enfermagem traduz-se para o enfermeiro como valor essencial à sua prática, por permitir cientificidade ao cuidar e garantir a universalidade da linguagem para toda a equipe.

Com certeza esses instrumentos traduziram a minha prática. É uma forma assim da gente mostrar que se tem planejamento com referencial, com um embasamento, que nada é tirado de trás da orelha. É uma forma de estar mostrando que nosso trabalho também tem um por que de tudo, tem um planejamento, um embasamento. Dá para perceber diferença no pós-operatório imediato; a diferença de quem recebe a VPO sistematizada com a teoria de base e quem só recebe a VPO sem a teoria. Eu observo que eles estão mais tranquilos, redução de ansiedade, medo, insegurança. (Enfermeiro 1)

Aliás, desde a prescrição, com as abordagens que nós estávamos fazendo, até mesmo o paciente demonstrou no pós o quanto as intervenções foram boas, por que antes ele não sabia, não tinha a menor ideia do que ia acontecer. (Enfermeiro 2)

Eu senti com a construção dos diagnósticos e das intervenções uma visibilidade melhor do cuidado, de como fazer, de conseguir enxergar de maneira mais científica o que é proposto realmente para a enfermagem, as intervenções para os diagnósticos traçados, né? As intervenções são bastante diretas e fica fácil até para o técnico de enfermagem aplicar nas 24 horas anteriores à cirurgia. (Enfermeiro 3)

A habilidade com os impressos e com a teoria adotada pode ser desenvolvida mediante o comprometimento atitudinal dos enfermeiros, sendo externada a partir da vitória dos primeiros momentos de dificuldade.

Depois que a gente começou (a lidar com NANDA, NIC e $\mathrm{NOC}$ ) eu consegui visualizar com mais facilidade e, hoje, eu tenho mais ainda. A gente tem que lançar mão mesmo das ferramentas, por que quando a gente usa, a gente consegue construir melhor o cuidado. Eu sinceramente fiquei muito satisfeita de trabalhar com esses instrumentos, por que eu senti a importância deles para a minha prática. (Enfermeiro 3)

\section{DISCUSSÃO}

A partir da análise dos resultados, pode-se apreender que o cuidado de enfermagem desde a VPO até o findar do pré-operatório imediato para o usuário, é avaliado positivamente. De fato, os pacientes que vivenciam sentimentos negativos antes da cirurgia cardíaca e que recebem orientação pré-operatória, experimentam melhores experiências no pós-operatório no tocante aos âmbitos físico e psicossocial. A perspectiva de 
minimização do medo e angústia traduz-se em melhor recuperação pós-operatória e consequente redução do tempo de internação hospitalar, evitando infecções e reduzindo custos institucionais ${ }^{(13)}$.

Comumente relatada como um sentimento que acompanha o pré-operatório de cirúrgica cardíaca, a ansiedade teve significativa redução com a utilização de musicoterapia ${ }^{(14)}$ e educação pré-operatória(15), evidenciando que propostas alternativas podem fazer parte do cuidado de enfermagem que antecede o procedimento cirúrgico. Nesta acepção, a comunicação interpessoal emerge como atividade que deve ser prioritária no perioperatório de cirurgia $\operatorname{cardíaca}^{(16)}$, por considerar que esta qualifica a assistência de enfermagem a partir do cuidado-orientação ao usuário. Entretanto, observa-se que mesmo em meio às atividades técnicas, o enfermeiro abstém-se do uso desta ferramenta ${ }^{(17)}$.

Outra abstenção profissional diz respeito à aplicação da SAE por meio das etapas do processo de enfermagem. Desafios como a falta de conhecimento dos modelos conceituais e teóricos, número reduzido de recursos humanos e materiais, além da intensa demanda de atividades assistenciais e administrativas, são comumente relatados ${ }^{(18)}$.

Contudo, no presente estudo, ao dimensionar suas ações de cuidado a partir de um referencial teórico transpessoal e das taxonomias que instrumentalizam a SAEP no período considerado, o enfermeiro obteve maior satisfação laboral, pela condição que os instrumentos permitiram de visualização do cuidado prestado por toda a equipe de enfermagem, conferindo autonomia e visibilidade do processo de cuidar, o que valorou sua atuação e destacou-o sobremaneira no cenário institucional.

Aliada à habilidade do enfermeiro, a utilização da SAE fundamentada na Teoria do Cuidado Transpessoal mostra-se como um suporte para qualificar o cuidado de enfermagem e criar um ambiente terapêutico centrado no paciente em direção ao alcance dos resultados anteriormente pretendidos na elaboração do processo de enfermagem ${ }^{(19)}$.

Logo, perceber o usuário no escopo de suas necessidades físicas, emocionais, espirituais e sociais, demanda do profissional uma constante atualização de subsídios teóricos capazes de oferecer resultados favoráveis a partir dos diagnósticos e intervenções implementadas.

Por outro lado, destaca-se a percepção de enfermeiros ao apontar a SAE como instrumento teórico distanciado da prática, o que conduz à compreensão da formação profissional lacunar quanto à perspectiva problematizadora e de aliança entre o saber-fazer acadêmico. Esta realidade imprime fragilidades consideráveis em torno da Ciência da Enfermagem, considerada ainda em construção ${ }^{(20)}$. Alguns efeitos negativos da ausência do cuidado sistematizado são o desconhecimento das necessidades do usuário, falta de qualidade assistencial e de visibilidade do enfermeiro ${ }^{(18)}$.

Em paralelo a esta discussão e tomando-se como base os resultados da presente pesquisa, reforça-se a clareza que a SAE orientada por um referencial teórico e pelas taxonomias confere ao processo de trabalho do enfermeiro. A satisfação do usuário pode ser apreendida pelo profissional a partir da avaliação dos resultados (NOC) das intervenções (NIC) propostas, revelando também aumento do enfrentamento a partir do conhecimento das informações que antes lhe eram duvidosas, bem como o autocontrole do medo e da ansiedade.

Ademais, o coeficiente de Pearson maior que 0,7 denotou o quanto o usuário percebeu o cuidado de enfermagem prestado e o avaliou satisfatoriamente, percebendo-se com maior capacidade de enfrentamento do processo saúde-doença. Este resultado converge com a proposição da Teoria do Cuidado Transpessoal, a qual favorece a libertação de sentimentos e permite que o paciente melhore a assimilação de si, de estar em situação de doença cardíaca com vistas à reestruturação ou recomposição (healing) ${ }^{(21)}$.

Este referencial teórico tem como precípuas a interatividade e intersubjetividade no momento do cuidado. Para tal concretude, o enfermeiro deve unir-se ao ser de quem se cuida, em uma relação que percebe o todo formado pela mente, corpo e espírito ${ }^{(21)}$. Por meio da análise de conceito, evoca-se a percepção dos enfermeiros deste estudo, em que no momento de cuidado explicitam a possibilidade de união com o paciente por meio da operacionalização e instrumentalização que os auxiliaram.

Neste sentido, o roteiro proposto pelo estudo considerou os aspectos científicos e humanos da profissão, ressignificando a atividade do profissional consciente e preocupado com a dignidade humana em direção ao olhar específico sobre o seu eixo principal: o cuidado ontológico em um paradigma transcendente para os sujeitos envolvidos.

Acredita-se que a limitação do conhecimento em torno desta temática seja uma das principais responsáveis pela inaplicabilidade no cotidiano laboral do enfermeiro. Torna-se fundamental a aproximação do ensino e pesquisa com a assistência, desenvolvendo a habilidade necessária para o manejo dos instrumentos de coleta de dados, diagnósticos, intervenções e resultados, à luz de uma teoria que traduza o cuidar em enfermagem, vencendo a dicotomia do saber-fazer.

\section{CONCLUSÃO}

Desvelar os significados do relacionamento interpessoal terapêutico entre enfermeiro/usuário, a partir da adoção da Teoria do Cuidado Transpessoal, sobre a visita pré-operatória de enfermagem após a vivência do processo cirúrgico permitiu: 1) identificar que os impressos baseados no referencial teórico/filosófico foram capazes de captar as necessidades dos usuários quando abordados terapeuticamente na VPO; 2) que os enfermeiros dispusessem de respaldo para definir a conduta terapêutica de forma individualizada diante das situações emergentes a partir das informações coletadas por ele a ponto de subsidiar a realização do julgamento clínico e a aplicação do raciocínio diagnóstico; 3) que os diagnósticos identificados e as intervenções implementadas foram avaliadas pelos usuários como favoráveis ao enfrentamento do processo cirúrgico durante o trás e pós-operatório cardíaco e 4) que os próprios enfermeiros avaliaram positivamente o uso do referencial teórico de Watson e das taxonomias NNN na medida em que estes referenciais conferiram visibilidade, cientificidade e autonomia à sua prática clínica. 


\section{REFERÊNCIAS}

1. Ministério da Saúde (BR). Saúde Brasil 2008: 20 anos de Sistema único de Saúde (SUS) no Brasil [Internet]. Brasília (DF): Ministério da Saúde; 2009 [acesso em 19 de dezembro de 2012]. Disponível em: bvsms.saude.gov.br/ bvs/publicacoes/saude_brasil_2008.pdf

2. Nunes JKVRS, Figueiredo Neto JÁ, Sousa RML, Costa VLXC, Silva FMAM, Silva ELC, et al. Depression after CABG: a prospective study. Rev Bras Cir Cardiovasc [Internet]. 2013 [acesso em 19 de dezembro de 2012];28(4):491-7. Disponível em: www.scielo.br/pdf/ rbccv/v28n4/v28n4a13.pdf

3. Amorim TV, Salimena AMO, Melo MCSC, Souza IEO. Emoções manifestas pelo ser-mulher-no-mundo após cirurgia cardíaca. Cogitare Enferm. 2013;18(2):268-73.

4. Amorim TV, Salimena AMO, Melo MCSC, Souza IEO, Silva LF. Sentidos do ser-aí-mulher-após-cirurgia-cardíaca à luz de Heidegger. Rev RENE. 2013;14(5):988-95.

5. Frias TFP, Costa CMA, Sampaio CEP. O impacto da visita pré-operatória de enfermagem no nível de ansiedade de pacientes cirúrgicos. REME Rev Min Enferm. 2010;14(3):345-52.

6. Souza LR, Souza MAG, Pinto AS, Cortez EA, Carmos TG, Nascimento RM. Os benefícios da visita pré- operatória de enfermagem para o cliente cirúrgico: revisão sistemática de literatura. Rev Pesqui Cuid Fundam [Internet] 2010 [acesso em 12 de junho de 2012];2(2):797806. Disponível em: www.seer.unirio.br/index.php/ cuidadofundamental/article/.../593

7. Conselho Federal de Enfermagem (COFEN). Resolução n. 358, de 15 de outubro de 2009. Dispõe sobre a Sistematização da Assistência de Enfermagem e a implementação do Processo de Enfermagem em ambientes, públicos ou privados, em que ocorre o cuidado profissional de Enfermagem, e dá outras providências [Internet]. Diário Oficial da União 23 out 2009 [acesso em 12 de junho de 2012]. Disponível em: http://www.diariodasleis.com.br/busca/ exibelink.php?numlink $=212736$

8. Watson J. Caring as the essence and science of nursing and health care. Mundo Saúde. 2009;33(2):143-9.

9. Silva CMC, Valente GSC, Bitencourt GR, Brito LN. Teoria do cuidado transpessoal na enfermagem: análise segundo Meleis. Cogitare Enferm [Internet] 2010 [acesso em 12 de junho de 2012];15(3):548-51. Disponível em: http://ojs. c3sl.ufpr.br/ojs2/index.php/cogitare/article/view/18902

10. Favero L, Meier MJ, Lacerda MR, Mazza VA, Kalinowski LC. Aplicação da Teoria do Cuidado transpessoal de Jean Watson: uma década de produção brasileira. Acta Paul Enferm [Internet]. 2009 [acesso em 12 de junho de 2012];22(2):2138. Disponível em: http://www.scielo.br/scielo.php?pid= S0103-21002009000200016\&script $=$ sci_abstract \&tlng $=\mathrm{pt}$
11. Carvalho NV, Neta DSR, Silva GRF, Araújo TME. O processo Clinical Caritas de Jean Watson na assistência de enfermagem brasileira: uma revisão sistemática. Cult Cuid [Internet]. 2011 [acesso em 12 de junho de 2012];15(29):82-8. Disponível em: http://rua.ua.es/dspace/ bitstream/10045/17456/1/Cultura_Cuidados_29_09.pdf

12. Lüdke M. Pesquisa em educação: abordagens qualitativas. São Paulo (SP): EPU; 2013.

13. Guo P. Preoperative educations interventions to reduce anxiety and improve recover among cardiac surgery patients: a review of randomized controlled trials. J Clin Nurs [Internet]. 2014 [cited 2012 june 12]. Available from: http://www.ncbi.nlm.nih.gov/pubmed/24894181

14. Lee KC, Chao YH, Yiin JJ, Chiang PY, Chao YF. Effectiveness of different music-playing devices for reducing preoperative anxiety: a clinical control study. Int J Nurs Stud [Internet]. 2011 [cited 2012 june 12];48:1180-7. Available from: http://www.ncbi.nlm.nih.gov/pubmed/21565344

15. Pott FS, Stahlhoefer T, Felix JVC, Meier MJ. Medidas de conforto e comunicação nas ações de cuidado de enfermagem ao paciente crítico. Rev Bras Enferm. 2013;66(2):174-9.

16. Gonçalves RMDA, Pereira MER, Pedrosa LAK, Silva QCG, Abreu RMD. A comunicação verbal enfermeiro-paciente no perioperatório de cirurgia cardíaca. Ciênc Cuid Saúde. 2011;10(1):27-34.

17. Guo P, East L, Arthur A. A preoperative education intervention to reduce anxiety and improve recovery among Chinese cardiac patients: a randomized controlled trial. Int J Nurs Stud [Internet]. 2012 [cited 2012 june 12];49(2):129-37. Available from: http://www.ncbi.nlm. nih.gov/pubmed/21943828

18. Medeiros AL, Santos SL, Cabral RWL. Desvelando dificuldades operacionais na Sistematização da Assistência de Enfermagem na perspectiva da Grounded Theory. Rev Eletrônica Enferm [Internet]. 2013 [acesso em 22 de junho de 2012];15(1):44-53. Disponível em: http://revistas.ufg. br/index.php/fen/article/view/15323

19. Faber K. Relationship-based care in the neonatal intensive care unit. Creat Nurs [Internet]. 2013 [cited 2012 june 22];19(4):214-8. Available from: http://www.ncbi.nlm. nih.gov/pubmed/24494389

20. Carvalho V. Sobre a identidade profissional na enfermagem: reconsiderações pontuais em visão filosófica. Rev Bras Enferm. 2013;66(n. esp.):24-32.

21. Favero L, Pagliuca LMF, Lacerda MR. Cuidado transpessoal em enfermagem: uma análise pautada em modelo conceitual. Rev Esc Enferm USP [Internet]. 2013 [acesso em 22 de junho de 2012];47(2):500-5. Disponível em: http://www.scielo.br/scielo.php?script=sci_arttext\&pid $=$ S0080-62342013000200032 